\title{
Conductor Development for High Field Dipole Magnets
}

\author{
R. M. Scanlan,D.R. Dietderich, and H. C. Higley, Lawrence Berkeley National Laboratory, Berkeley, CA., USA
}

\begin{abstract}
Historically, improvements in dipole magnet performance have been paced by improvements in the superconductor available for use in these magnets. The critical conductor performance parameters for dipole magnets include current density, piece length, effective filament size, and cost. Each of these parameters is important for efficient, cost effective dipoles, with critical current density being perhaps the most important. Several promising magnet designs for the next hadron collider or a muon collider require fields of $12 \mathrm{~T}$ or higher, i.e. beyond the reach of $\mathrm{NbTi}$. The conductor options include $\mathrm{Nb}_{3} \mathrm{Sn}, \mathrm{Nb}_{3} \mathrm{Al}$, or the high temperature superconductors. Although these conductors have the potential to provide the combination of performance and cost required, none of them have been developed sufficiently at this point to satisfy all the requirements. This paper will review the status of each class of advanced conductor and discuss the remaining problems that require solutions before these new conductors can be considered as practical. In particular, the plans for a new program to develop $\mathrm{Nb}_{3} \mathrm{Sn}$ and $\mathrm{Nb}_{3} \mathrm{Al}$ conductors for high energy physics applications will be presented. Also, the development of a multikiloamp Bi-2212 cable for dipole magnet applications will be reported.
\end{abstract}

\section{CONDUCTOR FOR FIELDS BELOW $10 \mathrm{~T}$}

$\mathrm{NbTi}$ is the conductor of choice for accelerator magnets for fields below $10 \mathrm{~T}$. This has been due to availability, cost, long piece lengths, and performance. A series of superconducting accelerators, starting with the Tevatron [1], HERA [2], and more recently, LHC [3], and RHIC [4], have relied on $\mathrm{NbTi}$. In addition, the SSC planned to use $\mathrm{NbTi}$, and significant advances in performance as well as conductor reliability and cost resulted from the SSC R\&D program [5]. For example, the conductor $\mathrm{J}_{\mathrm{c}}$ specification $(5.0 \mathrm{~T}, 4.2 \mathrm{~K})$ was increased from $1800 \mathrm{~A} / \mathrm{mm}^{2}$ for the Tevatron to $2750 \mathrm{~A} / \mathrm{mm}^{2}$ for the SSC. The best values for fine filament $\mathrm{NbTi}$ actually exceeded the SSC specification, with values of large size billets exceeding $3000 \mathrm{~A} / \mathrm{mm}^{2}$ and $\mathrm{R} \& \mathrm{D}$ efforts producing values over $3700 \mathrm{~A} / \mathrm{mm}^{2}$ [6].

Near the end of the SSC R\&D phase (1986), several groups focused on pushing $\mathrm{NbTi}$ to new limits via the artificial pinning center (APC) approach. Rather than rely on a cold work and precipitation process to produce alpha-Ti phase precipitates which act as flux pinning centers, the APC approach seeks to introduce a fine dispersion of second phase particles by mechanical processing. This research showed great promise, especially for increasing the $\mathrm{J}_{\mathrm{c}}$ values at low and moderate fields. Samples prepared at the Univ. of Wisconsin showed $\mathrm{J}_{\mathrm{c}}$ values exceeding $5000 \mathrm{~A} / \mathrm{mm}^{2}$ at $5 \mathrm{~T}$ [7]. Commercial attempts also showed early promise. Supercon, Inc. provided APC wire for two magnets at LBNLa solenoid [8] which reached $8.6 \mathrm{~T}$ and a dipole [9] which reached $9.0 \mathrm{~T}$ at $1.8 \mathrm{~K}$. Supercon also delivered some APC $\mathrm{NbTi}$ conductor to a magnet manufacturer for evaluation in MRI magnets [10]. However, at this time, the early promise of APC NbTi has not been realized in any large-scale application. This is partly a question of timing--the LHC project was into production and the SSC project was cancelled before the APC material could be fully commercialized. Also, some of the cost advantages of the APC approach have not been realized due to the high cost of some components, such as thin $\mathrm{Nb}$ sheet. Although some groups in Japan remain interested in APC NbTi for low field AC applications, the accelerator magnet frontier has moved on to higher fields and interest in NbTi in general is not high.

A similar scenario holds for the ternary alloy NbTiTa. Basic studies [11] and some early commercialization efforts showed promise. An R\&D program was initiated at Fermi National Accelerator Laboratory to develop the ternary alloy for the Tevatron interaction quadrupoles, but the effort was stopped when it was shown that the binary $\mathrm{NbTi}$ conductor could produce the required field gradient. Interest in the ternary was revived at FNAL at the beginning of the LHC high gradient quadrupole program when the requirement was for a very high gradient (above $250 \mathrm{~T} / \mathrm{m}$ ) and high operating field. However, this requirement has been relaxed to about $220 \mathrm{~T} / \mathrm{m}$--a value that can be reached by the binary $\mathrm{NbTi}$ alloy. Also, the optimization of the ternary alloy for high field performance was hampered by problems in getting ternary alloy material. At present, no significant R\&D aimed at optimizing NbTiTa for High Energy Physics applications is continuing.

\section{CONDUCTOR FOR FIELDS ABOVE $10 \mathrm{~T}$}

For fields above $10 \mathrm{~T}$, a new approach to magnet design and fabrication is required, since all the materials available-$\mathrm{Nb}_{3} \mathrm{Sn}, \mathrm{Nb}_{3} \mathrm{Al}, \mathrm{Bi}-2212, \mathrm{Bi}-2223$, and $\mathrm{YBCO}$, are brittle
This work was supported by the Director, Office of Energy Research, Office of High Energy and Nuclear Physics, High Energy Physics Division, U.S. Department of Energy, under Contract No. DE-AC0376SF00098. 
compounds and thus require special handling and processing. Two magnet fabrication alternatives are being considered. In the first, "wind and react", the coils are wound when the conductor components are still ductile, i.e. before the reaction step where the brittle superconducting phases are formed. This method has been used for a number of dipole magnets $[12,13,14]$. However, it requires the development of special insulation and coil structural components that can withstand the high reaction temperatures associated with the formation of the superconducting phases. For $\mathrm{Nb}_{3} \mathrm{Sn}$, with a reaction temperature in the range of 650-700 $\mathrm{C}$, this requirement can be met with fiberglass insulation and structural materials such as stainless steel. However, $\mathrm{Nb}_{3} \mathrm{Al}$ may require a somewhat higher reaction temperature for optimum properties, e.g. 800 $\mathrm{C}$, and a different insulation is required. Moreover, the $\mathrm{Bi}$ 2212 and 2223 options require even higher reaction temperatures and in addition must be reacted in an oxygen atmosphere, which puts more restrictions on both insulation and structural choices.

In light of these difficulties, new magnet designs are being developed which are more "conductor friendly" than the designs developed using NbTi conductors. In particular, a new design known as the "common coil" [15] has large diameter ends and may be amenable to a different fabrication approach. In this approach, called "react and wind", the conductor is reacted after conductor fabrication, i.e. wire drawing and cabling, is complete, but before coil winding. The reacted conductor is then wound into the magnet coils, with careful handling and maintaining adequate bending diameters to prevent conductor damage. The react and wind technique has been used to construct small solenoids for NMR applications, where small diameter wires can be used, and also for large fusion magnet coils, where the bending diameters are large and the conductors are robust. However, accelerator magnets have posed a more challenging problem, since the large stored energy precludes the use of small wires, while at the same time, the small magnet apertures, typically 30-50 mm, require the conductors to undergo a tight bend at the ends of the magnets. In the common coil approach, one coil is used to produce the field in two apertures, which can be widely spaced, e.g. $200 \mathrm{~mm}$ apart (Fig. 1). This means that the bending diameter at the magnet end is $200 \mathrm{~mm}$ rather than $20-30 \mathrm{~mm}$ of the traditional "cosine theta" design. A proof of principal test of this design has been completed successfully using a wind and react approach, and a high field version is under construction at LBNL $[15,16]$. Also, common coil react and wind magnets are being designed by Brookhaven National Laboratory [17] and by a collaboration involving FNAL and LBNL [18].

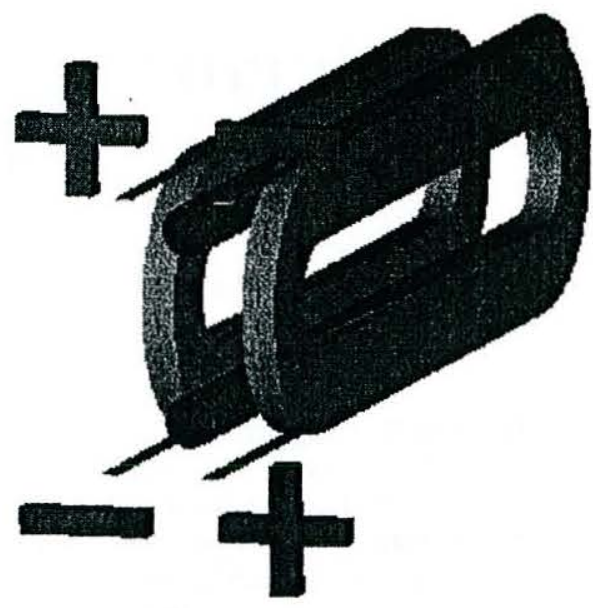

Fig. 1 Schematic of Common Coil Design Showing Large Bending Diameter at the Magnet Ends

\section{A. $\quad \mathrm{Nb}_{3}$ Sn-present status}

Of the potential conductors for high field dipole applications, $\mathrm{Nb}_{3} \mathrm{Sn}$ is in the most advanced state of development. This is due largely to the investment made by the magnetic confinement fusion programs over the past 20 years, culminating with the ITER (International Thermonuclear Test Reactor) model coil which has just been completed. The ITER program, together with a small but growing NMR magnet business, has provided some financial incentive for the conductor manufacturers. However, with the completion of the ITER program, it has become necessary for the High Energy Physics program to provide increased support for the $\mathrm{Nb}_{3} \mathrm{Sn}$ industrial programs. Also, the technical requirements for accelerator magnets are substantially different from the fusion requirements, as shown in Table 1. Here, the ITER specification is listed and compared with key parameters of the two most recent LBNL accelerator magnets--D20 and RD3. Note that the conductors for accelerator magnet application have a very high Jc requirement--over twice that required for the ITER conductor. Note also that the accelerator magnet conductors do not have an ac loss specification at this time. The loss for one wire has been measured [19] and is shown for comparison.

Table 1. Comparison of Critical Parameters for ITER and Accelerator Magnet Conductors

\begin{tabular}{|c|c|c|c|c|}
\hline Type & $\begin{array}{l}\text { Wire } \\
\text { diam. } \\
(\mathrm{mm})\end{array}$ & $\begin{array}{l}\mathrm{Cu} \\
\text { volume } \\
(\%)\end{array}$ & $\begin{array}{l}\mathrm{J}_{\mathrm{c}} \\
(12 \mathrm{~T}, 4.2 \mathrm{~K}) \\
\left(\mathrm{A} / \mathrm{mm}^{2}\right)\end{array}$ & $\begin{array}{l}\text { AC } \\
\text { Losses } \\
(\mathrm{mJ} / \mathrm{cc},+/ 3 \mathrm{~T})\end{array}$ \\
\hline ITER HP1 & 0.8 & 60 & $>700$ & $<600$ \\
\hline $\begin{array}{l}\text { D20 Inner } \\
\text { TWCA } \\
\text { IGC }\end{array}$ & $\begin{array}{l}0.75 \\
0.75\end{array}$ & $\begin{array}{l}50 \\
30 \\
\end{array}$ & $\begin{array}{l}1400 \\
877\end{array}$ & $\cdots$ \\
\hline $\begin{array}{l}\text { D20 Outer } \\
\text { TWCA }\end{array}$ & 0.48 & 52 & 1550 & $\cdots$ \\
\hline RD3 Inner & 0.8 & 51 & 1981 & $\cdots$ \\
\hline RD3 Outer & 0.8 & 60 & 2190 & 5000 \\
\hline
\end{tabular}


Three U.S. Laboratories are developing high field $\mathrm{Nb}_{3} \mathrm{Sn}$ magnets for accelerator applications, and are purchasing conductor with specifications similar to those listed for RD3. Two manufacturers, Intermagnetics General Corp (IGC) and Oxford Superconducting Technology (OST), are providing conductor for these programs. Most recently, OST has delivered conductor for RD3 with the properties listed in Table 1. This represents the present "state of the art". Although the $\mathrm{J}_{\mathrm{c}}$ improvements compared with ITER and also D20 are impressive, most of the improvement is a result of increasing the volume fraction of $\mathrm{Nb}_{3} \mathrm{Sn}$ in the conductor cross section with little improvement in the intrinsic $\mathrm{J}_{\mathrm{c}}$ of the $\mathrm{Nb}_{3} \mathrm{Sn}$. Recent R\&D results on thin film samples indicate that significant intrinsic improvements in $\mathrm{J}_{\mathrm{c}}$ are possible [20]. A problem that is associated with attaining higher $\mathrm{J}_{\mathrm{c}}$ by increasing the volume fraction of $\mathrm{Nb}_{3} \mathrm{Sn}$ is that the tendency of filaments to sinter together during heat treatment is increased, so that magnetization effects become large. The micrograph for the wire used in RD3 is shown in Fig 2 and the magnetization results are shown in Fig. 3. This micrograph shows the reason for the large losses--with this high volume fraction of $\mathrm{Nb}$ and $\mathrm{Sn}$ in the multifilamentary bundle, the individual filaments are fused together so that the effective filament size is the subelement size, e.g. about 70 micron in this case. This is one of the issues that will be addressed in the $\mathrm{Nb}_{3} \mathrm{Sn}$ development program described below. Although this does not have a strong effect on the immediate R\&D program, it can be a problem for any proposed accelerator due to the field distortion that results at injection. If the intrinsic $\mathrm{Nb}_{3} \mathrm{Sn} \mathrm{J}_{\mathrm{c}}$ can be increased, the filaments can be spaced apart so that they do not grow together, and magnetization effects will be diminished.

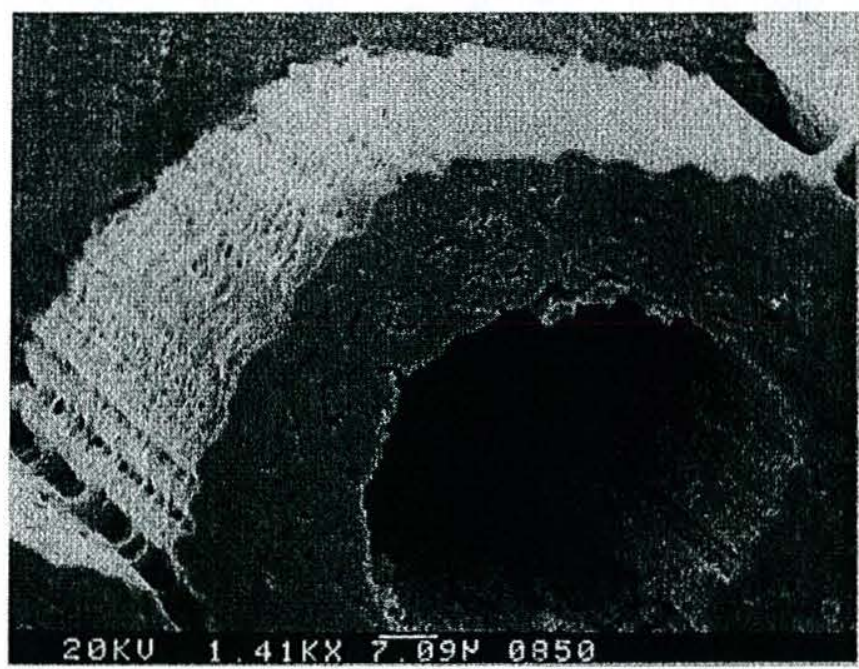

Fig. $2 \mathrm{Nb} 3 \mathrm{Sn}$ subelement from conductor supplied by OST for RD3. The matrix has been removed by etching to reveal $\mathrm{Nb}_{3} \mathrm{Sn}$ filaments which have fused together.

In addition to the magnetization problem, the $\mathrm{Nb}_{3} \mathrm{Sn}$ state of the art represented by the RD3 conductor presents two other problems. The first is piece length; the average piece length is $565 \mathrm{~m}$ for the inner grade and $357 \mathrm{~m}$ for the outer grade conductor. This short piece length reduces the effective yield of cable, and also increases manufacturing costs for the strands due to the increased labor required. In addition, the high $\mathrm{J}_{\mathrm{c}} \mathrm{Nb}_{3} \mathrm{Sn}$ is being made in small process batches, e.g. $25 \mathrm{~kg}$, at present. This results in an unrealistically high cost for the $\mathrm{Nb}_{3} \mathrm{Sn}$ conductor. These factors are an inconvenience for the R\&D programs at present, and will be a serious concern for any large scale accelerator project.

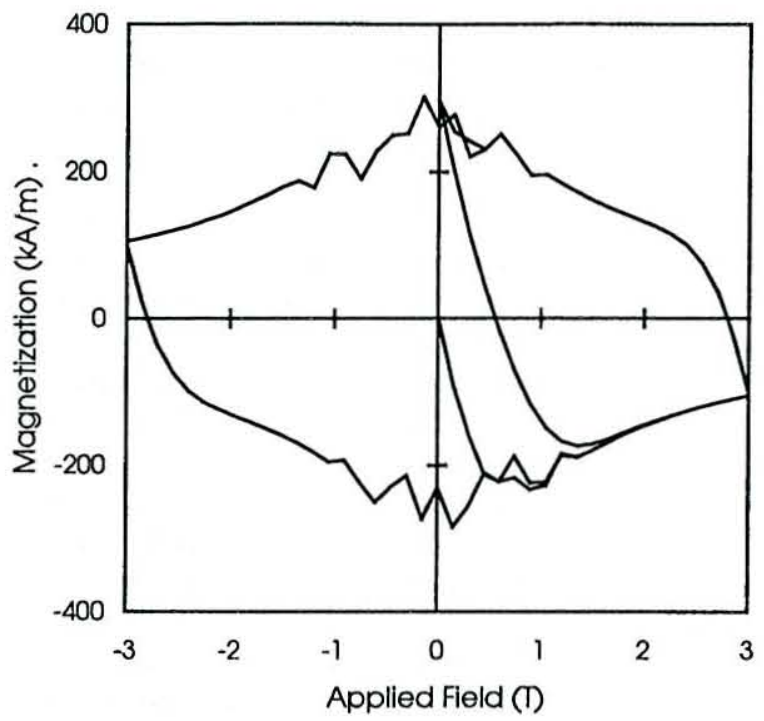

Fig. 3. Magnetization curve for the conductor shown in Fig.2. Note the presence of flux jump behavior at low applied fields. [18]

\section{B. $N b_{3}$ Sn-new development program}

This situation with $\mathrm{Nb}_{3} \mathrm{Sn}$ is prompting work in two areas--a vigorous new conductor development program to improve $\mathrm{Nb}_{3} \mathrm{Sn}$, and a study of the alternatives to $\mathrm{Nb}_{3} \mathrm{Sn}$. The goal of the conductor development program is to bring the cost-effectiveness of $\mathrm{Nb}_{3} \mathrm{Sn}$, as measured by $\$ / \mathrm{kA}-\mathrm{m}$, to a level comparable to that of NbTi. For reference, the cost of $\mathrm{NbTi}$ wire for the SSC was $\$ 1.05 / \mathrm{kA}-\mathrm{m}$ for inner grade wire at $7 \mathrm{~T}$. In order to meet this goal, the cost of $\mathrm{Nb}_{3} \mathrm{Sn}$ strand must be reduced, and the $\mathrm{J}_{\mathrm{c}}$ at the magnet operating field must be improved. The critical current goal is 3000 $\mathrm{A} / \mathrm{mm}^{2}$ at $12 \mathrm{~T}$, which is to be compared with the OST value for the RD3 conductor of $2200 \mathrm{~A} / \mathrm{mm}^{2}$. The R\&D results [20] show that this improvement would occur, for example, if the $\mathrm{Nb}_{3} \mathrm{Sn}$ grain size can be reduced from a typical value of $40 \mathrm{~nm}$ to $30 \mathrm{~nm}$. The manufacturing challenge is to obtain this improvement while at the same time not affecting the other important properties or the manufacturing costs. The cost goal is to reduce the cost of $\mathrm{Nb}_{3} \mathrm{Sn}$ strand from the present small batch R\&D price of $\$ 700 / \mathrm{kg}$ to a large process unit, high volume price of $\$ 200 / \mathrm{kg}$. A cost analysis based on the raw materials prices and process units comparable to present $\mathrm{NbTi}$ manufacturing practice indicate that this cost improvement is reasonable as well.

The new R\&D program will have two phases--the first phase will last approximately 3 years and will focus on 
intrinsic property improvements and proof of principal experiments on process improvements. Intrinsic property improvements of most interest are $\mathrm{J}_{\mathrm{c}}$, magnetization, and strain effects. Proof of principal process improvements will focus on identifying fabrication processes that will result in longer piece lengths, larger billet sizes, and more cost effective processing. One important guideline for selecting proposals for this phase is that the work should not duplicate the ongoing work being funded by the Small Business Innovative Research (SBIR) program. One of the aims of this program is to supplement the SBIR work by funding projects which cannot qualify for SBIR funds, for example, companies that cannot qualify for SBIR funding due to their size. Another guideline for selecting proposals is that the approaches proposed should have the potential of significant improvements in properties or cost reduction, and not be merely incremental improvements on the established fabrication processes. An example of the type of innovation that can have significant cost improvements is the removal of $\mathrm{Cu}$ from the $\mathrm{Nb}_{3} \mathrm{Sn}$ strand fabrication process. In the proposed process, basic $\mathrm{Nb}_{3} \mathrm{Sn}$ strand is fabricated with only a minimum amount of $\mathrm{Cu}$ (some proposals set this minimum at zero). The $\mathrm{Cu}$ necessary for protection will then be added in a cabling step as the final process step, rather than adding the $\mathrm{Cu}$ early in the fabrication process and then carrying this $\mathrm{Cu}$ through the remaining process steps, as is now the case. This new approach has two cost benefits. First, the labor costs are directly related to the volume of material being processed, whether it is superconductor or $\mathrm{Cu}$. Second, the engineering design, and quality control costs are greatly reduced when the strand manufacturer is fabricating only one product, i.e., low-Cu strand. However, several new conditions introduced with this processing approach must be assessed. First, the costs of adding the $\mathrm{Cu}$ in a cabling process must be compared with the cost savings generated by this new wire fabrication approach. Second, the effectiveness of the $\mathrm{Cu}$ for protection in this new configuration must be evaluated. Current sharing between superconductor and $\mathrm{Cu}$ strands must be uniform and the current transfer lengths must be reasonable in order for this new conductor to function properly in a magnet. These issues will be addressed in the proposed conductor development program.

\section{C. $\mathrm{Nb}_{3} \mathrm{Al}$}

For very high field dipoles where the transverse stress may exceed $150 \mathrm{MPa}$, the magnet designer has two choices. First, techniques for limiting the stress on the conductor, called stress management [21], can be employed, albeit at the expense of overall current density and magnet efficiency. Second, $\mathrm{Nb}_{3} \mathrm{Al}$ can be substituted for $\mathrm{Nb}_{3} \mathrm{Sn}$. Although $\mathrm{Nb}_{3} \mathrm{Al}$ is a brittle intermetallic compound of the same structure type as $\mathrm{Nb}_{3} \mathrm{Sn}$, it has one major advantage: the dependence of the critical current on strain is much less than for $\mathrm{Nb}_{3} \mathrm{Sn}$ [22]. For example, at $12 \mathrm{~T}$, after an intrinsic strain of $0.3 \%$ has been applied, the critical current of $\mathrm{Nb}_{3} \mathrm{Sn}$ decreases to only $60 \%$ of its original value, while
$\mathrm{Nb}_{3} \mathrm{Al}$ retains $95 \%$ of its original critical current under the same conditions. However, at present, the $\mathrm{Nb}_{3} \mathrm{Al}$ that is available in long lengths has a $\mathrm{J}_{\mathrm{c}}(12 \mathrm{~T}, 4.2 \mathrm{~K})$ of only 600 $\mathrm{A} / \mathrm{mm}^{2}$, and thus is not competitive with $\mathrm{Nb}_{3} \mathrm{Sn}$. A new process for fabricating $\mathrm{Nb}_{3} \mathrm{Al}$, called the "rapid quench" process, is under development. However, this process represents significant process control and scale-up challenges. The wires must be heated to near the melting point e.g. $1900 \mathrm{C}$ and then rapidly quenched to retain a bcc phase that has limited ductility. Then, high conductivity $\mathrm{Cu}$ must be added for protection and the $\mathrm{Nb}_{3} \mathrm{Al}$ wires must be cabled to produce a high current conductor. Finally, the cable must be insulated and wound into a coil, followed by reaction at 750-800 $\mathrm{C}$ to produce the superconducting A15 phase, assuming a wind and react process is followed. At present, only $50 \mathrm{~m}$ lengths of wire have been produced using this technique, although vigorous programs are underway in Japan [22] and the U.S. [23], to produce long, continuous lengths by this process.

\section{D. $B i-2223$ and 2212}

Three HEP magnet development groups are investigating the possible application of HTS conductors to high field dipole magnets. LBNL [24], together with industrial collaborators at Intermagnetics General Corp., Oxford Superconducting Technology, and Showa Electric Wire and Cable, are developing a multikiloamp Rutherford-type cable anlalogous to the $\mathrm{NbTi}$ and $\mathrm{Nb}_{3} \mathrm{Sn}$ cables used at present. TAMU [25] is developing an armored cable of Bi2212 strands that can withstand high transverse stresses. $\mathrm{BNL}$ [17] is using reacted $\mathrm{Bi}-2212$ and $\mathrm{Bi}-2223$ tape conductors to wind racetrack coils. Although these projects are small and just getting underway, some early results are available in the references cited above.

The goal of the BNL program is to utilize the form of HTS conductor that is most readily available, i.e. thin tapes, to wind racetrack coils. Since the common coil geometry is most amenable to the tape geometry, the BNL program is focusing on this type of magnet. A major problem is magnet protection in this case where the individual tapes at present have an critical current limitation of 100-200 $\mathrm{A}$ in fields of $12-15 \mathrm{~T}$. This presents a significant challenge for magnet protection due to the high coil inductance that results when low current conductors are used. Possible solutions to this problem include using multiple layers of tapes in parallel or increasing the current density for the tapes. Ultimately, the BNL program hopes to acquire YBCO tapes in long lengths and with the extremely high current densities demonstrated in short length samples.

Significant progress has been made in producing Rutherford-type cables for accelerator dipole applications. As shown in Fig 4, several types of Rutherford-type cables have been produced. Initially, cables were made with metal cores, since the early wires had limited ductility and the core was necessary to prevent wire breakage at the edges of the cables. As the wire ductility improved, cables with a 
thin ceramic core and coreless cables were produced. Each type of cable
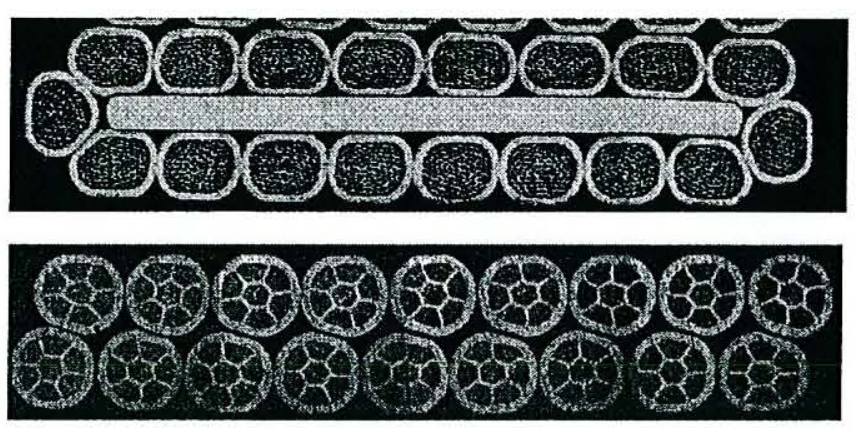

Fig. 4. Two types of Rutherford-type cables made from Bi-2212 strands, the upper using a Nichrome metal core and the lower made without a core.

has some attractive features--the metal core provides some additional strength and may be attractive, especially for react and wind type coils. The ceramic core provides high interstrand resistance and hence low ac losses without the space penalty of the metal core. The coreless cable provides the highest overall current density where ac losses or added strength are not important issues. Progress in attaining high Ic in cables is shown in Fig. 5. The improvement in cable 614A compared with cable 614 resulted from reduced contamination when a ceramic wrap was applied over the Nichrome core. The improvement in cable 685 represents improved wire performance.

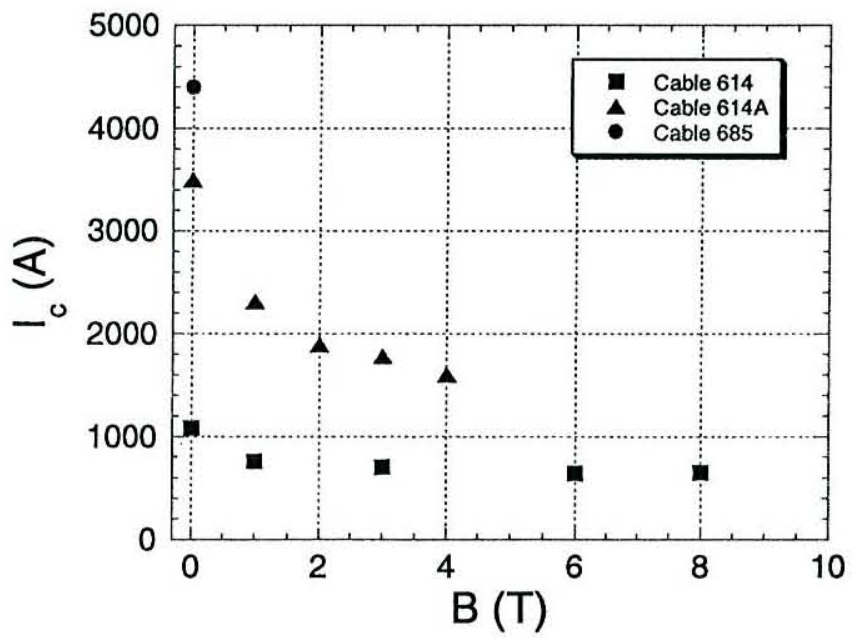

Fig. 5. Critical current vs. field for Rutherford cables. The changes which produced the improved performance are described in the text.

One of the concerns with HTS conductors for application to accelerator magnets is the potential $I_{c}$ degradation due to the transverse loads that result from the Lorentz forces on the coils. Measurements are in progress to determine the effects of transverse stress on the Rutherford-type cables described above [26]. In addition, this concern is being addressed in the TAMU program with the development of an "armored cable" conductor. Bi-2212 strands are used to form a cable around a central tube (which acts as a spring), and the cable is then inserted into a protective tube. The combination of the outer structural tube and the inner spring tube prevents the $\mathrm{Bi}-2212$ strands from being subjected to high transverse stresses. Progress on this approach will be presented in another paper at this conference [25].

\section{SUMMARY AND CONCLUSIONS}

As the focus of accelerator magnet R\&D moves beyond the LHC and $10 \mathrm{~T}$, the challenge is to build cost-effective magnets from a new class of superconductors. Although proof of principle demonstrations using $\mathrm{Nb}_{3} \mathrm{Sn}$ as a prototypical brittle material have been successful, much remains to be done before the goals of a reliable and costeffective high field dipole magnet are accomplished. The first task is to improve the intrinsic conductor performance and develop more cost effective manufacturing processes to meet the goals described in Section II. The next task is to develop new magnet designs that can best utilize the brittle superconductors. Finally, these two must be combined to yield the reliable and cost-effective magnet that is the goal of this new program.

\section{ACKNOWLEDGMENTS}

The authors would like to acknowledge the assistance of colleagues at LBNL in the preparation of this paper. In addition, much of the information was first discussed or presented at the ongoing series of Conductor Workshops that are cosponsored by the Univ. of Wisconsin and LBNL as part of their HEP conductor development programs.

\section{REFERENCES}

[1] R.A.Lundy, "State of the Energy Doubler", IEEE Trans. On Magnetics, MAG-17 (1981), 709.

[2] R. Meinke,"Superconducting Magnet System for HERA", IEEE Trans on Magnetics, Mag-27 (1991), 1728.

[3] R. Perin, "The Superconducting Magnet System for the LHC", IEEE Trans. On Magnetics, Mag-27 (1991), 1735.

[4] M.A. Harrison, "Commissioning Results from RHIC", proceedings of the $18^{\text {th }}$ Particle Accelerator Conference, paper MOAC2, New York City, March, 1999, to be published.

[5] R.M. Scanlan, "The Evolution of Tooling, Techniques, and Quality Control for Accelerator Dipole Magnet Cables", IEEE Trans. On Applied Superconductivity $\underline{3}$ (1993), 842 .

[6] P.J. Lee and D.C. Larbalestier, "An Examination of the Properties of SSC Phase II R\&D Strands", IBID, 833.

[7] L. Cooley et al, "Strongly Enhanced Critical Current Density in Nb47wt.\%Ti Having a Highly Aligned Microstructure", Applied Physics Letters $\underline{58},(1991), 2984$.

[8] R.M. Scanlan et al, "Characterization and Coil Test Results for a Multifilamentary $\mathrm{NbTi}$ Conductor Using Artificial Pinning Center Technology", IEEE Trans on Applied Superconductivity $\underline{3}$ (1993), 1358. [9] R.M. Scanlan et al, "Evaluation of APC NbTi Superconductor in a Model Dipole Magnet", IEEE Trans. On Magnetics 30 (1994), 1627.

[10] C. Renaud et al, "Commercial Application of NbTi Superconductor Employing Artificial Pinning Centers", IEEE Trans on Applied Superconductivity $\underline{5}$ (1995), 1189 .

[11] D.G. Hawksworth and D.C. Larbalestier, Enhanced values of Hc2 in $\mathrm{Nb}-\mathrm{Ti}$ ternery and quaternary alloys", Adv. In Cryo. Eng. 26, 1980, p.479. [12] A. Asner et al, "First $\mathrm{Nb}_{3} \mathrm{Sn} 1-\mathrm{m}$ long Superconducting Dipole Magnet for LHC Breaks the 9.5 T Threshold", Proc. Of MT-11, Tsukuba, 1992, p.36. 
[13] A. den Ouden et al, "Application of $\mathrm{Nb}_{3} \mathrm{Sn}$ Superconductors in High Field Accelerator Magnets", Trans. On Applied Superconductivity 1 (1997), 733.

[14] A.D. Mcinturff et al, "Test Results for a High Field (13T) $\mathrm{Nb}_{3} \mathrm{Sn}$ Dipole", Proc. Particle Accelerator Conf., Vancouver, 1997, p.3212.

[15] R. Gupta, "A Common Coil Design for High Field 2-in-1 Accelerator Magnets", 1997 Particle Accelerator Conf., Vancouver, (1997) ,3344.

[16] S.A. Gourlay, "Design and Fabrication of a $14 \mathrm{~T}, \mathrm{Nb}_{3} \mathrm{Sn}$ Superconducting Racetrack Dipole Magnet", these proceedings.

[17] A.K. Ghosh et al, "A Common Coil Magnet for Testing High Field Superconductors, Proc. Particle Accelerator Conf., New York, 1999, to be published.

[18] G. Ambrosio et al, "Study of the Reaction and Wind Technique for a $\mathrm{Nb}_{3} \mathrm{Sn}$ Common Coil Dipole", these proceedings.

[19] R.W. Goldfarb, private communication.

[20] D.R. Dietderich et al, "High Critical Current Densities in $\mathrm{Nb}_{3} \mathrm{Sn}$ Films with Engineered Microstructures", Adv. In Cryo. Eng. 44 (1998), 951.

[21] A. Abreu et al, "Block-coil Dipole for Future Hadron Colliders", Trans. On Applied Superconductivity 9 (1999), 705.

[22] N. Harada et al, "Microstructures and Flux Pinning Properties in $\mathrm{Nb}_{3} \mathrm{Al}$ Tapes by Ohmic-Heating Method", IEEE Trans. On Applied Superconductivity 9 (1999), 1429.

[23] F. Buta et al, "Short-sample Quenching of $\mathrm{Nb}_{3} \mathrm{Al}$ Precursor Strand in Support of Reel-to-Reel Process Development", IEEE Trans. On Applied Superconductivity 2 (1999), 1433.

[24] R.M .Scanlan et al, "Fabrication and Test Results for Rutherford-type Cables Made From BSCCO Strands", Trans. On Applied Superconductivity 9 (1999) 130.

[25] P. Mcintyre, "Strain Tolerant Cable Using Bi-2212 Superconductor", these proceedings

[26] D.R. Dietderich, private communication. 